\title{
Estradiol Inhibits Depolarization-Evoked Exocytosis in PC12 Cells via N-Type Voltage-Gated Calcium Channels
}

\author{
Kelly L. Adams • Marc M. Maxson • \\ Lisa Mellander • Remco H. S. Westerink • \\ Andrew G. Ewing
}

Received: 25 May 2010/ Accepted: 2 September 2010/Published online: 19 November 2010

(C) Springer Science+Business Media, LLC 2010

\begin{abstract}
Fast neuromodulatory effects of $17-\beta$-estradiol (E2) on cytosolic calcium concentration $\left(\left[\mathrm{Ca}^{2+}\right]_{i}\right)$ have been reported in many cell types, but little is known about its direct effects on vesicular neurotransmitter secretion (exocytosis). We examined the effects of E2 on depolarization-evoked $\left[\mathrm{Ca}^{2+}\right]_{i}$ in PC12 cells using fluorescence measurements. Imaging of $\left[\mathrm{Ca}^{2+}\right]_{i}$ with FURA-2 revealed that depolarization-evoked calcium entry is inhibited after exposure to 10 $\mathrm{nM}$ and $10 \mu \mathrm{M}$ E2. Calcium entry after exposure to $50 \mu \mathrm{M}$ E2 decreases slightly, but insignificantly. To relate E2-induced changes in $\left[\mathrm{Ca}^{2+}\right]_{i}$ to functional effects, we measured exocytosis using amperometry. It was observed that E2 in some cells elicits exocytosis upon exposure. In
\end{abstract}

A commentary to this article can be found at doi:10.1007/s10571-010-9611-z.

K. L. Adams and M. M. Maxson contributed equally to the work.

K. L. Adams · A. G. Ewing

Department of Chemistry, The Pennsylvania State University, 104 Chemistry Research Building, University Park,

PA 16802, USA

\section{M. Maxson · A. G. Ewing}

The Huck Institutes of the Life Sciences, Neuroscience Institute, The Pennsylvania State University, University Park,

PA 16802, USA

\section{K. L. Adams · L. Mellander · A. G. Ewing ( $₫)$}

Department of Chemistry, University of Gothenburg,

Kemivägen 10, 41296 Göteborg, Sweden

e-mail: Andrew.ewing@chem.gu.se

\section{R. H. S. Westerink ( $\square)$}

Neurotoxicology Research Group, Institute for Risk Assessment Sciences, Utrecht University, P.O. Box 80.177,

3508 TD Utrecht, The Netherlands

e-mail: R.westerink@uu.nl addition, E2 inhibits depolarization-evoked exocytosis with a complex concentration dependence, with inhibition at both physiological and pharmacological concentrations. This rapid inhibition amounts to $45 \%$ at a near physiological level (10 nM E2), and 50\% at a possible pharmacological concentration of $50 \mu \mathrm{M}$. A small percentage (22\%) of cells show exocytosis during E2 exposure ("Estrogen stimulated"), thus vesicle depletion could possibly account (at least partly) for the E2-induced inhibition of depolarization-evoked exocytosis. In cells that do not exhibit E2-stimulated release ("Estrogen quiet"), the E2-induced inhibition of exocytosis is abolished by a treatment that eliminates the contribution of $\mathrm{N}$-type voltage-gated calcium channels (VGCCs) to exocytosis. Overall, the data suggest that E2 can act on N-type VGCCs to affect secretion of neurotransmitters. This provides an additional mechanism for the modulation of neuronal communication and plasticity by steroids.

Keywords Catecholamine secretion - Calcium channels . Calcium homeostasis - Amperometry $\cdot 17-\beta$-Estradiol .

Exocytosis

$\begin{array}{ll}\text { Abbreviations } \\ \text { E2 } & 17-\beta \text {-Estradiol } \\ \text { ER- } \beta & \text { Beta form of the estrogen receptor } \\ \text { GPR30 } & \text { Membrane estrogen receptor } \\ \text { PC12 } & \text { Pheochromocytoma cells } \\ \text { VGCC } & \text { Voltage-gated calcium channel }\end{array}$

\section{Introduction}

$17-\beta$-estradiol (E2) is a potent steroid that exerts its effects via nuclear transcription factors that regulate gene expression as well as via membrane-bound receptors that 
modulate intracellular signaling pathways. E2 is synthesized in the gonads as well as locally in the brain, where it exerts numerous neuromodulatory effects, including modulation of synaptic plasticity, neuroprotection, and synaptogenesis (McCarthy 2008; Kelly and Rønnekleiv 2009; Nilsen 2008; Ogiue-Ikeda et al. 2008).

Within seconds, E2 can alter neuronal activity and second messenger systems, including kinase-signaling pathways, calcium mobilization and entry and vesicular neurotransmitter secretion (exocytosis) (Kelly and Rønnekleiv 2009). However, the proposed mechanisms by which E2 influences the cytosolic calcium concentration $\left(\left[\mathrm{Ca}^{2+}\right]_{i}\right)$ and subsequent exocytosis vary and are not well understood. Understanding how E2 affects exocytosis both at physiological and pharmacological levels could provide important insights into related adaptive neuronal processes affected by E2 as well as its therapeutic potential.

PC12 cells have been used frequently as a model to study the presynaptic exocytosis machinery. PC12 cells secrete dopamine from large dense-core vesicles, permitting detection of individual vesicle release events with carbon fiber amperometry (Chen et al. 1994; Westerink and Ewing 2008). They have been used as a model system to study both voltage-gated calcium channels (VGCCs) and intracellular calcium release mechanisms (Bennett et al. 1998; Taylor and Peers 1999; Tully and Treistman 2004). Importantly, PC12 cells are also an appropriate model system to study the effects of estrogens. They express ER- $\beta$ but lack ER- $\alpha$ in an undifferentiated state (Nilsen et al. 1998) and also contain the membrane estrogen receptor GPR30 (unpublished observations). Others have shown that micromolar concentrations of E2 inhibit secretion in PC12 (Kim et al. 2000) and adrenal chromaffin cells (Machado et al. 2002), but the effects of physiological levels $(\sim 10 \mathrm{nM})$ of $\mathrm{E} 2$ on secretion have not been specifically examined in $\mathrm{PC} 12$ cells.

In this article, we report the effects of both physiological $(\mathrm{nM})$ and higher pharmacological $(\mu \mathrm{M})$ levels of E2 on exocytosis evoked by elevated extracellular $\mathrm{K}^{+}$, a stimulus that activates VGCCs and thereby increases $\left[\mathrm{Ca}^{2+}\right]_{i}$. The results indicate that E2 suppresses exocytosis with a complex concentration dependence via a pathway that involves N-type VGCCs and in specific cells potentially depletes the readily releasable pool of vesicles.

\section{Methods}

Materials

$17-\beta$-Estradiol (E2) was purchased from Calbiochem (San Diego, CA). FURA-2 AM was purchased from Invitrogen
(Carlsbad, CA). All other reagents were purchased from Sigma-Aldrich (St. Louis, MO).

\section{Solutions}

The experimental bathing solution was HEPES-buffered saline, containing (in $\mathrm{mM}$ ) $150 \mathrm{NaCl}, 5 \mathrm{KCl}, 2 \mathrm{CaCl}_{2}, 1.2$ $\mathrm{MgCl}_{2}, 10$ HEPES, and 5 glucose (pH 7.4). The high $\mathrm{K}^{+}$ depolarizing solution had the same composition as the saline only with $\mathrm{KCl}$ raised to $100 \mathrm{mM}$ and $\mathrm{NaCl}$ lowered to $55 \mathrm{mM}$ to maintain osmotic balance. For treatments, drugs were dissolved into the HEPES-buffered saline with the addition of $0.1 \%$ ethanol to dissolve E2 and $\omega$-conotoxin. This concentration of ethanol had no effect on exocytosis in control experiments (data not shown).

\section{Cell Culture}

PC12 cells (Greene and Tischler 1976) were purchased from the American Type Culture Collection (www.atcc. org) and maintained in phenol red-free RPMI 1640 (Mediatech/VWR: West Chester, PA) supplemented with 10\% equine serum (Hyclone: Logan, UT), 5\% fetal bovine serum (Hyclone: Logan, UT), and 100 units/ml Penicillin/ Streptomycin (Gibco-Invitrogen: Carlsbad, CA). Cells were grown in collagen IV-coated flasks incubated at $7 \%$ $\mathrm{CO}_{2}$ and $37^{\circ} \mathrm{C}$, and subcultured every $7-9$ days or when confluence was reached. Experiments were performed on cells 4-7 days after subculturing.

\section{Carbon Fiber Amperometry}

Electrodes were prepared as described previously (Kozminski et al. 1998). In brief, 5- $\mu$ m diameter carbon fibers were threaded into glass pipettes via aspiration and pulled using a commercial puller (P-97, Sutter Instruments, Novato, CA) to create a seal around the tip of the fiber. Electrode tips were cut to a uniform diameter of $8 \mu \mathrm{m}$ (larger than the fiber diameter because of the encasing glass) with a razor and dipped for $5 \mathrm{~min}$ in epoxy (Epotek301 , Billerica, MA) prior to heating for $24-72 \mathrm{~h}$ at $100^{\circ} \mathrm{C}$. On the day of experiments, electrode tips were beveled at $45^{\circ}$ to produce a smooth electroactive disk surface using a commercial micropipette beveler (Model BV-10, Sutter Instruments, Novato, CA). Beveled electrode tips were maneuvered to the surface of individual cells and lowered until the electrode surface made contact with the cell, indicated by a slight deformation of the cell surface. Detection of catecholamine release was performed by holding the potential of the electrode at $+700 \mathrm{mV}$ versus an $\mathrm{Ag} / \mathrm{AgCl}$ reference electrode placed in the bathing solution. Electrodes were tested immediately before and after each experiment in $100 \mu \mathrm{M}$ dopamine to ensure that 
sensitivity was maintained. Results were discarded from experiments where electrode sensitivity was lost.

Cells were plated on $60 \mathrm{~mm}$ collagen IV-coated dishes, and the experiments were performed at $37^{\circ} \mathrm{C}$ using an Olympus IX-70 inverted microscope and heat stage (Linkam Scientific, London, UK). Prior to electrochemical recording, cells were washed three times with fresh, warm $\left(37^{\circ} \mathrm{C}\right)$ saline. Micropipettes were pulled using a commercial puller, back-filled with test solutions (high $\mathrm{K}^{+}$ stimulation solution or E2) and cut to $\sim 15 \mu \mathrm{m}$ O.D. These pipettes were positioned $\sim 100 \mu \mathrm{m}$ from the experimental cell and solutions were ejected onto the cell (Picospritzer II, General Valve Corp). Three successive 5-s pulses of $100 \mathrm{mM} \mathrm{K}^{+}$were applied at 40-s intervals. The concentration of this stimulation was modeled after the early experiments with estrogen on exocytosis (Lopez et al. 1991), and modified to conform to more recent protocols using PC12 cells as models for exocytosis (Sombers et al. 2004, 2007; Westerink and Ewing 2008). Next, the recording was suspended, and the electrode was raised from the cell for $10 \mathrm{~min}$ to allow the cell to recover. This recovery period was intended to limit the effects of desensitization to the stimulus during the experiment. After the recovery period, the electrode was placed against the cell surface again, and a 45-s pulse of E2 was applied. A 45-s pulse was chosen to adequately expose the cell to the treatment solution as well as to prevent any genomicrelated effects brought about by prolonged exposure. Following exposure to E2 treatment, the cell received three additional successive 5-s pulses of $100 \mathrm{mM} \mathrm{K}^{+}$. To estimate changes in exocytosis over time in the absence of any treatment, a control ratio was calculated from a set of untreated cells with the same 10-min recovery interval between each set of stimulations. In situations where the objective was to eliminate the involvement of N-type VGCCs, $\omega$-conotoxin GVIA was added directly to the bathing solution throughout the duration of the experiment.

\section{Electrochemical Data Acquisition and Analysis}

Amperometric data were recorded with an Axon 200B amplifier (Molecular Devices, Sunnyvale, CA). The output was digitized at $5 \mathrm{kHz}$ and filtered at $2 \mathrm{kHz}$ with an internal four-pole Bessel filter, and analyzed without subsequent filtering. Peaks were counted and characterized with the MiniAnalysis software detection algorithm (Synaptosoft, Decatur, GA). Peaks were detected if both the amplitude of local maxima and the area under the curve exceeded a threshold of five times the root-meansquared noise for a flat, 2-s recording acquired at the beginning of each experiment (Colliver et al. 2000). Peaks were visually inspected to confirm that electrical noise was not included and to include peaks manually that were not detected because of their proximity in the current trace. Overlapping events were discarded if the baseline for each peak could not be extrapolated using a built-in software algorithm. In cases where peaks appeared to rise above a broader background current, the detection algorithm assigned a baseline for the peak to the level of the background current.

Changes in depolarization-evoked exocytosis following treatment was calculated as a treatment ratio according to

Treatment ratio $=\frac{\text { No. of events after treatment }}{\text { No. of events before treatment }}$

with the number of events summed from a cell stimulated three times with $100 \mathrm{mM} \mathrm{K}^{+}$for both the numerator and denominator. In determining this ratio, each cell serves as its own control. Where inhibition is compared to control in the text, percent inhibition was calculated as

Percent inhibition $(\%)=100-\frac{\text { Treatment ratio }}{\text { Control ratio }} \times 100$

Because the number of evoked peaks per cell can vary from 20 to 400 events, cells are best represented by averaging ratios from each cell rather than pooling pre- and posttreatment peaks from all cells prior to averaging (Colliver et al. 2000; Westerink et al. 2000), and were thus analyzed in this manner. Two-tailed $t$ tests were used to compare all treatment groups, and Dunnett's $t$ test was used to compare a range of E2 concentrations to control; $P$-values $<0.05$ were considered significant. All data are expressed as mean \pm SEM of $n$ single cell experiments.

\section{Intracellular Calcium Imaging and Analysis}

PC12 cells were subcultured on 60-mm collagen IV-coated dishes. Cells were loaded with $1 \mu \mathrm{M}$ FURA-2 in saline for $15 \mathrm{~min}$ at $37^{\circ} \mathrm{C}$ and $7 \% \mathrm{CO}_{2}$. After loading, cells were washed three times with fresh, warm $\left(37^{\circ} \mathrm{C}\right)$ saline. Experiments were conducted at $37^{\circ} \mathrm{C}$ and as outlined in the "Carbon Fiber Amperometry" section with the exception that the cells were subjected to $45 \mathrm{~s}$ of saline instead of treatment as a control. Ratiometric fluorescence imaging data (excitation at 340 and $380 \mathrm{~nm}$ ) were collected at 510-nm emission wavelength. Data were analyzed using Olympus Cell-R and its accompanying software (Olympus, Hamburg, Germany) to calculate a F340/F380 FURA ratio that is used to monitor changes in $\left[\mathrm{Ca}^{2+}\right]_{i}$.

FURA ratio $=\frac{F_{\text {intensity }(340)}}{F_{\text {intensity }}(380)}$

Data were background-subtracted using a cell-free region present in the field-of-view. FURA treatment ratios were calculated as 
FURA treatment ratio $=\frac{\text { Average FURA ratio }(\text { after })}{\text { Average FURA ratio }(\text { before })}$

where the average FURA ratio (after) is equal to the average of the peak ratios for the three $\mathrm{K}^{+}$stimulations after the treatment period and the average FURA ratio (before) is equal to the average of the peak ratios for the three $\mathrm{K}^{+}$stimulations before the treatment.

\section{Results}

\section{Estradiol Inhibits Depolarization-Evoked Calcium Influx}

To measure the effects of E2 on cellular calcium entry, three successive 5-s pulses of $100 \mathrm{mM} \mathrm{K}^{+}$were applied to depolarize the cells and evoke calcium entry through VGCCs. In all the cases, calcium entry was observed during $\mathrm{K}^{+}$stimulation. A small decrease $(13 \pm 6 \%)$ was observed in calcium influx with successive stimulations. This was used as the baseline, so that all changes after E2 treatment are relative to this small decrease in control cells. When cells were challenged $10 \mathrm{~min}$ after the initial $\mathrm{K}^{+}$stimulations with a 45-s application of E2 before a second round of three successive $\mathrm{K}^{+}$stimulations, the level of calcium entry decreased or showed no change relative to control (Fig. 1). $\mathrm{K}^{+}$-evoked calcium entry after exposure to $10 \mathrm{nM}$ E2 decreased by $26 \pm 3 \%(P<0.01)$ and by as much as $56 \pm 2 \%(P<0.001)$ after exposure to $10 \mu \mathrm{M} \mathrm{E} 2$. After exposure to $50 \mu \mathrm{M} \mathrm{E} 2$, however, $\mathrm{K}^{+}$-evoked calcium entry decreased only by $7 \pm 3 \%$ $(P=0.44)$.

\section{Estradiol Inhibits Depolarization-Evoked Exocytosis}

Exocytosis was measured using amperometry to investigate whether the observed changes in depolarization-evoked calcium entry have functional consequences for neurotransmitter secretion. Three successive 5-s pulses of $100 \mathrm{mM} \mathrm{K}^{+}$, applied at 40-s intervals, evoked massive exocytosis. On average, $176 \pm 13$ exocytotic events ( $n=129$ cells) were detected from three $5-\mathrm{s} \mathrm{K}^{+}$stimulations prior to any treatment. When cells were challenged 10 min later with different concentrations of E2 for $45 \mathrm{~s}$ before a second round of three successive stimulations, the number of $\mathrm{K}^{+}$-stimulated events either remained the same (Fig. 2a) or decreased (Fig. 2b). A small subset of cells (22\%) also showed release events during the E2 application (Fig. 2c), and these release events are important as they might deplete the vesicle pool for the $\mathrm{K}^{+}$stimulations after E2.
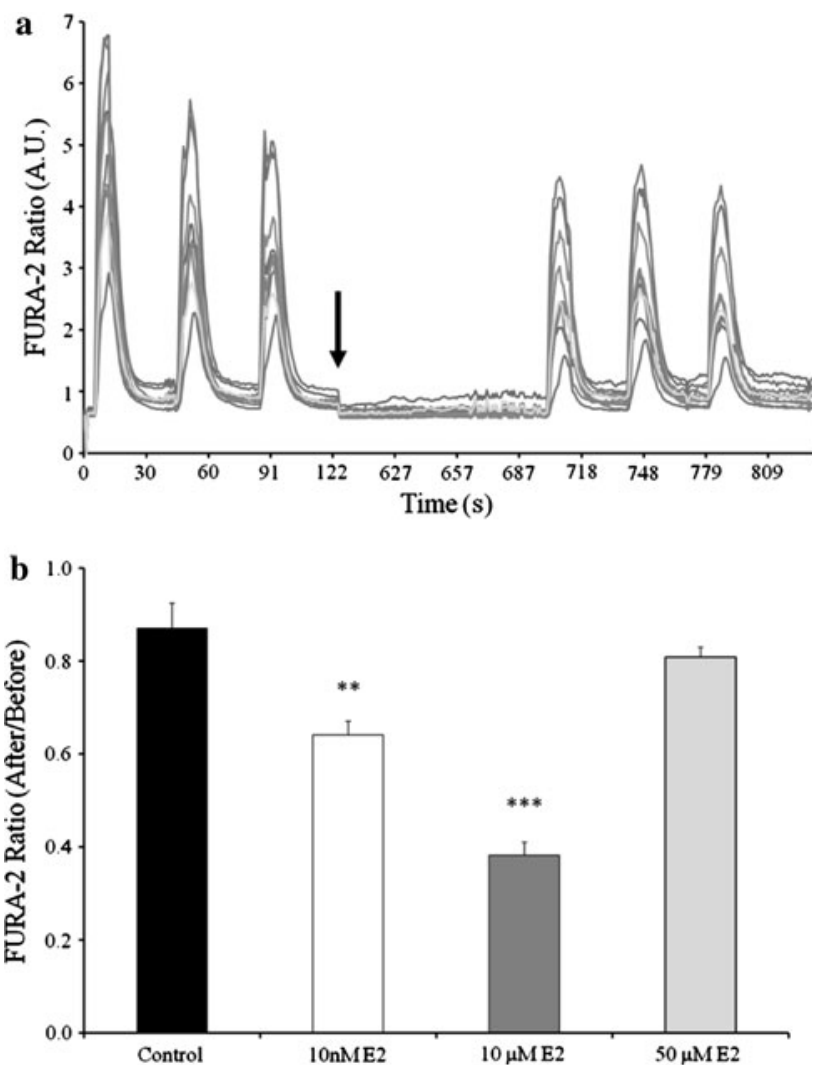

Fig. 1 Depolarization-evoked intracellular calcium levels are affected by E2 application. a Representative recording of $\left[\mathrm{Ca}^{2+}\right]_{i}$ for a dish of cells treated with saline as a control. Cells are challenged with three 5-s $100 \mathrm{mM} \mathrm{K}^{+}$stimulations applied every $40 \mathrm{~s}$ followed by a 10 -min break without treatment to allow the cells to recover (indicated by a break in the trace). The cells were then treated for $45 \mathrm{~s}$ with the appropriate concentration of E2 or saline as a control followed by three more $\mathrm{K}^{+}$stimulations. The $\mathrm{K}^{+}$stimulations rapidly increase the FURA-2 ratio, indicative for increases in $\left[\mathrm{Ca}^{2+}\right]_{i}$. b Bar graph of the FURA treatment ratio (Eq. 4) shows that when saline was administered during the drug treatment segment of the protocol as a control, $\left[\mathrm{Ca}^{2+}\right]_{i}$ slightly decreased compared to levels observed prior to the treatment period $(87 \pm 6 \%$ of the increase in ratio before). Treatment with $10 \mathrm{nM}$ E2 resulted in $26 \pm 3 \%$ less calcium entry versus the saline control $(* * P=0.005)$, while treatment with $10 \mu \mathrm{M}$ E2 resulted in a $56 \pm 2 \%$ decrease versus the control $(* * * P<0.001)$. Treatment with $50 \mu \mathrm{M}$ E2 resulted only in a slight (7 $\pm 3 \%)$, but not statistically different $(P=0.44)$ decrease in the amount of calcium entry post-treatment. Data collected from $n=80$, 40, 63, and 40 cells from 7, 4, 5, and 4 dishes for saline control, $10 \mathrm{nM} \mathrm{E} 2,10 \mu \mathrm{M} \mathrm{E} 2$, and $50 \mu \mathrm{M} \mathrm{E} 2$, respectively

To examine the change in exocytosis following treatment with E2, data from the three stimulations before E2 (serving as same-cell control) were compared to those after E2 treatment (Fig. 3). The data shown with the solid line compares the number of events observed after treatment to the number of events observed before treatment (Eq. 1). Treatment with E2 inhibited the amount of $\mathrm{K}^{+}$-stimulated exocytosis in a complex manner with a maximum inhibition of $63 \pm 7 \%$ at $50 \mu \mathrm{M}$ compared to control. Application of E2 at physiologically relevant levels (10 nM) also 


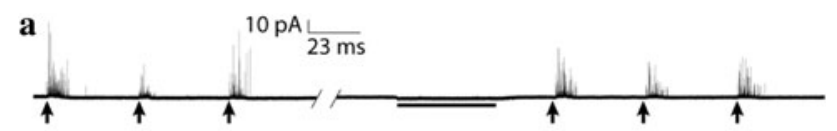

b
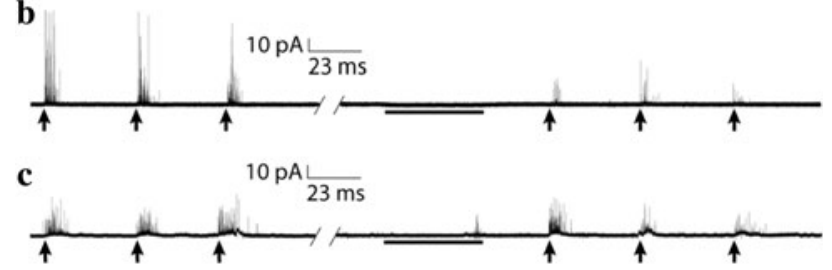

Fig. 2 Representative amperometric traces of exocytosis. PC12 cells were stimulated three times for $5 \mathrm{~s}$ with $100 \mathrm{mM} \mathrm{K}^{+}$(denoted by arrows). The cells were then allowed to recover for $10 \mathrm{~min}$ (denoted as a break in the trace). Cells were subsequently exposed to a 45-s pulse of E2 of different concentration or only the HEPES-buffered saline (indicated by a solid line along the time axis) followed by three more 5-s stimulations with $100 \mathrm{mM} \mathrm{K}^{+}$. Cells generally responded one of three ways: a Amperometric trace of a cell treated with $100 \mathrm{nM}$ E2. The number of events after E2 exposure was approximately the same as the number of events seen before E2 exposure. No events were observed during the application of E2. b Amperometric trace of another cell treated with $100 \mathrm{nM}$ E2. The number of events after E2 exposure dramatically decreased as compared to the number of events before E2 exposure. Again no events were seen during the application of E2. c Amperometric trace of a cell treated with $100 \mathrm{pM}$ E2. The number of events after treatment was slightly reduced after E2 exposure as compared to the number of events before E2 exposure. However, events were also observed during the E2 application. Cells with events during the E2 treatment, as shown in (c), are referred to as "Estrogen stimulated" cells in the text. Cells without events during the E2 treatment (a and b) are collectively referred to as "Estrogen-quiet" cells

resulted in a $44 \pm 8 \%$ inhibition, although intermediate concentrations $(1-5 \mu \mathrm{M})$ were not effective. There was a trend toward inhibition at $2.5 \mathrm{nM}(P=0.07)$ and $100 \mathrm{nM}$ E2 $(P=0.06)$ that did not reach statistical significance. Individual amperometric peaks did not vary in charge (area under the peak) or shape (rise time, decay time, half-width, and rise slope) after exposure to E2 at any concentration, indicating that E2 did not have any direct effects on the exocytosis machinery.

The dashed line in Fig. 3 compares the number of events observed both during and after treatment to the number of events observed before treatment (Eq. 5).

No. of events after treatment + No. of events during treatment

$$
\text { No. of events before treatment }
$$

These data suggest that release during application of E2, mainly at $10 \mathrm{nM}$ and $50 \mu \mathrm{M}$, might deplete the readily releasable pool of vesicles thereby affecting the number of release events observed during $\mathrm{K}^{+}$stimulation after the treatment. Data for E2 concentrations where these two curves differ, i.e., at $10 \mathrm{nM}$ and $50 \mu \mathrm{M}$, have, therefore, been sub-divided into two groups of cells: those with events during the treatment period ("Estrogen stimulated") and those without events ("Estrogen quiet"). An arbitrary threshold of less than five events during the treatment period was set for a cell to be categorized as "Estrogen quiet". A comparison of "Estrogen-stimulated" versus "Estrogen-quiet" cells for $10 \mathrm{nM}$ and $50 \mu \mathrm{M}$ E2 treatments is shown in Fig. 4. The treatment ratio for both groups was calculated using Eq. 5 and thus includes the release events during E2 treatment. Using this analysis, "Estrogen-stimulated" cells did not show inhibition of exocytosis at $10 \mathrm{nM}$ E2 compared to control, but rather an insignificant increase in the number of events observed. Likewise, "Estrogen-stimulated" cells show very little inhibition at $50 \mu \mathrm{M}$ E2 $(11 \pm 33 \%)$, whereas "Estrogenquiet" cells showed a $45 \pm 12 \%$ inhibition at $10 \mathrm{nM}$ E2 $(P=0.013)$ and a $50 \pm 16 \%$ inhibition at $50 \mu \mathrm{M}$ E2 $(P=0.022)$.

Inhibition of Exocytosis by Estradiol Depends on N-Type Voltage-Gated Calcium Channels

"Estrogen-stimulated" cells may have significant depletion of the number of readily releasable vesicles available, thus reducing the amount released during the subsequent $\mathrm{K}^{+}$ stimulations. Therefore, only "Estrogen-quiet" cells were used to further investigate the inhibitory effects of E2. Exocytosis initiated by depolarization with $\mathrm{K}^{+}$depends primarily on L- and N-type VGCCs in PC12 cells (Taylor and Peers 1999). We used the specific N-type VGCC antagonist, $\omega$-conotoxin GVIA (Hirning et al. 1988), to test whether the action of E2 on N-type VGCCs was sufficient to account for its inhibition of exocytosis. When $500 \mathrm{nM}$ $\omega$-conotoxin was present throughout the experiment, neither $10 \mathrm{nM}$ nor $50 \mu \mathrm{M}$ E2 inhibited exocytosis. The number of post-E2 exocytosis events was $102 \pm 11 \%$ of the pre-E2 events at $10 \mathrm{nM}$ and $104 \pm 16 \%$ at $50 \mu \mathrm{M}$ compared to untreated cells with $94 \pm 9 \%$ of initial activity over the same time interval (Fig. 5). However, when L-type VGCCs were blocked with nimodipine $(10 \mu \mathrm{M})$, exposure to $50 \mu \mathrm{M}$ E2 still inhibited exocytosis (not shown). The results suggest that N-type VGCCs are required for the inhibitory effects of E2 at $10 \mathrm{nM}$ and $50 \mu \mathrm{M}$, although other VGCCs and additional downstream targets could also be involved.

\section{Discussion}

This study demonstrates that brief exposure (45 s) to nearphysiological levels of E2 $(10 \mathrm{nM})$ rapidly alters depolarization-evoked $\mathrm{Ca}^{2+}$ entry in PC12 cells when compared to control experiments that were exposed to saline between $\mathrm{K}^{+}$stimulations (Fig. 1). Pharmacological levels of E2 


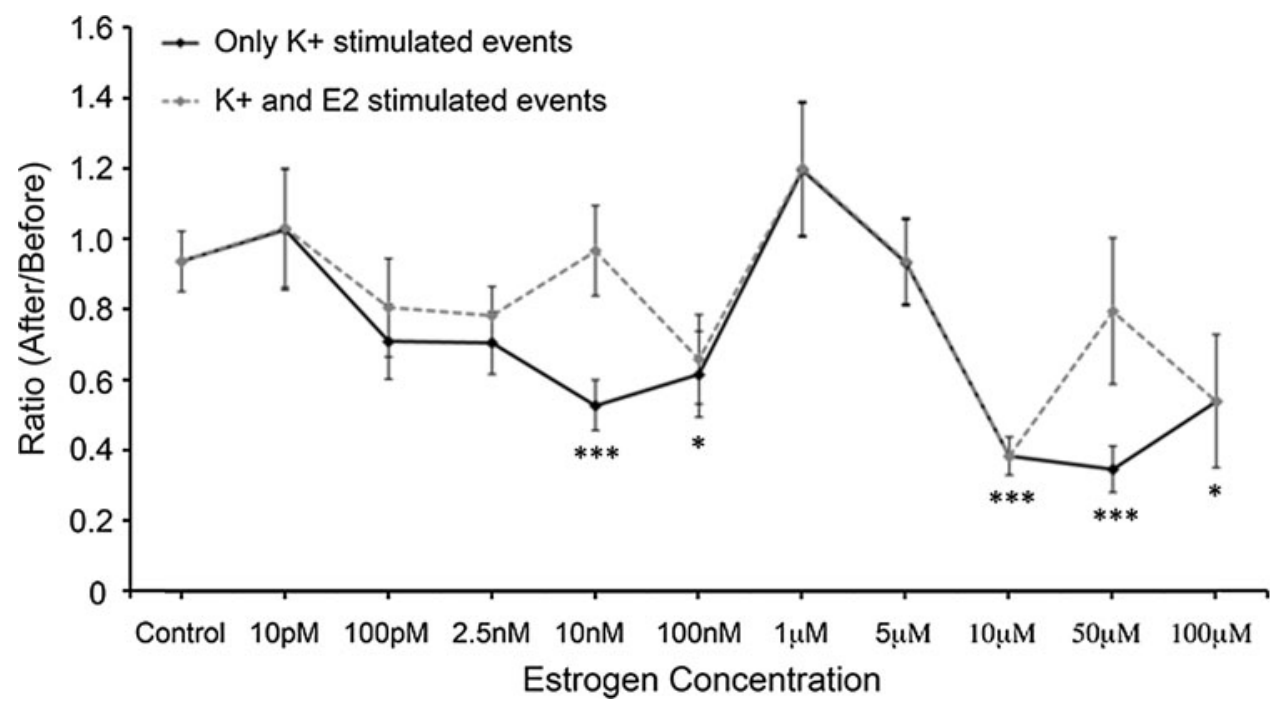

Fig. 3 Concentration-response curves for the effect of E2 on exocytosis. Treatment ratio (Eq. 1), indicated by the solid line, shows the data from all cells investigated. Exocytotic events that occurred in some cells during the E2 treatment were excluded from this curve. Both at a physiological concentration $(10 \mathrm{nM})$ and at possible pharmacological concentrations $(10-100 \mu \mathrm{M})$, E2 inhibits exocytosis. This inhibition is not observed at $10 \mathrm{nM}$ and $50 \mu \mathrm{M} \mathrm{E} 2$, however, when events during the $\mathrm{E} 2$ treatment period are also included in the ratio calculation to account for vesicle depletion from "Estrogen stimulated" cells (dashed line; see Eq. 5). Averages at each concentration are compiled from $n=16$ (control), $11(10 \mathrm{pM}), 9(100 \mathrm{pM}), 14$
(2.5 nM), $19(10 \mathrm{nM}), 12(100 \mathrm{nM}), 12(1 \mu \mathrm{M}), 6(5 \mu \mathrm{M}), 8(10 \mu \mathrm{M})$, $11(50 \mu \mathrm{M})$, and $11(100 \mu \mathrm{M})$ single cell experiments. $* P<0.05$ (for the primary concentration-response curve only at $100 \mathrm{nM}$ ); *** $P<0.001$. Of the 129 cells that make up the primary concentration-response curve (solid line) (including the 16 control cells), 29 cells were "Estrogen stimulated" (having $>5$ events during the E2 treatment period). This amounts to $\sim 22 \%$ of the cells examined. However, the bulk of these cells were within the 10-nM and 50- $\mu \mathrm{M} \mathrm{E2-}$ treated cells (13 and 7 cells, respectively). The remaining nine cells were for the $100 \mathrm{pM}$ E2 treatment (4 cells), $2.5 \mathrm{nM}$ E2 treatment (3 cells), $100 \mathrm{nM}$ E2 treatment (1 cell), and $1 \mu \mathrm{M} \mathrm{E2}$ treatment (1 cell)
$(10 \mu \mathrm{M})$ also induce a rapid and extensive inhibition of $\mathrm{Ca}^{2+}$ entry. Similarly, brief applications of E2 (10 nM or $10 \mu \mathrm{M})$ significantly reduced the number of exocytosis events in PC12 cells, whereas intermediate concentrations were without effect on exocytosis (Fig. 3). Levels of E2 in the micromolar and nanomolar range have been independently reported to affect exocytosis by a membranereceptor mechanism (Lopez et al. 1991; Machado et al. 2002; Lee et al. 2002; Kim et al. 2000), and our results are consistent with this. However, a complex concentrationresponse to $\mathrm{E} 2$ that encompasses both response ranges as shown here has not been reported.

Of interest, exocytosis was largely inhibited at higher E2 concentrations $(50-100 \mu \mathrm{M})$, while depolarization-evoked $\mathrm{Ca}^{2+}$ entry following $50 \mu \mathrm{M}$ E2 remained nearly constant, suggesting multiple processes might contribute to the observed E2-induced inhibition of exocytosis, and that these might differ for E2 exposure at low versus high concentrations. Our data not showing a decrease in $\mathrm{Ca}^{2+}$ influx at the high concentration of E2 appears to contradict that of Lopez et al., but it might mean that multiple $\mathrm{Ca}^{2+}$ sources are involved in the mechanism of E2 action. Further, in some cells "spontaneous" exocytosis was observed during the exposure to E2 ("Estrogen stimulated", see below), also pointing to the involvement of multiple processes.

A large body of literature confirms that E2 can rapidly modulate calcium and messenger systems in the picomolar to nanomolar range. Depending on cell type and concentration, E2 can activate PKC, PKA, or ERK1/2 MAP kinase on a rapid similar time scale (Kelly and Rønnekleiv 2009; Ogiue-Ikeda et al.,2008; Machado et al. 2002; Lee et al. 2002; Vasudevan and Pfaff 2007). Moreover, E2-induced activation of these pathway(s) has been shown to both enhance and inhibit neuronal activity, a similar effect to that observed in our model system.

In some cells, E2 at $10 \mathrm{nM}$ and $50 \mu \mathrm{M}$ elicits exocytotic release, which could (partly) explain the inhibition of subsequent depolarization-evoked exocytosis if vesicle depletion could occur. As a result, cells challenged at these concentrations were sub-divided into two groups: one with events during the E2 application ("Estrogen stimulated") and one without ("Estrogen quiet"). It is interesting to speculate that the difference between "Estrogen-stimulated" and "Estrogen-quiet" cells might involve differential expression of an estrogen receptor that facilitates E2-stimulated exocytosis. This release might involve initial opening, rather than restricting of calcium channels on the 


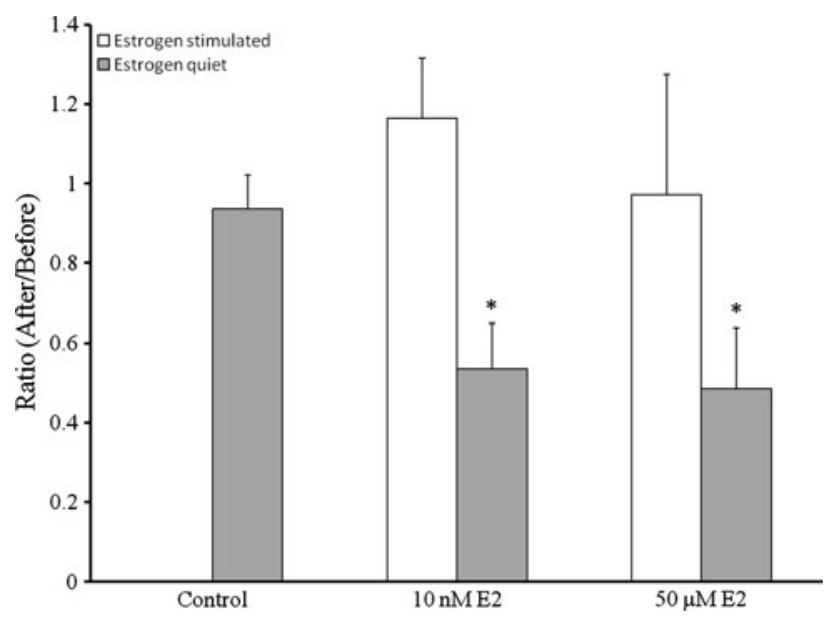

Fig. 4 Comparison of the effects of E2 on exocytosis for selected cell types. The number of events observed during $\mathrm{K}^{+}$stimulation after E2 treatment compared to the number of events before $\mathrm{E} 2$ treatment for cells treated with $10 \mathrm{nM}$ and $50 \mu \mathrm{M} \mathrm{E} 2$ and control. "Estrogen stimulated" contains cells having events during the E2 treatment period. "Estrogen quiet" contains cells having few or no events during the E2 treatment period. To calculate the ratio for "Estrogen stimulated", events observed during the E2 application were added to the number of events seen after E2 treatment, and this total was compared to the number of events seen prior to E2 treatment (Eq. 5). At $10 \mathrm{nM}$, E2 inhibited release by $45 \pm 12 \%$ for the "Estrogenquiet" cells. At $50-\mu \mathrm{M}$ E2, the inhibition for "Estrogen-quiet" cells was as high as $50 \pm 16 \%$. At these concentrations of E2, the E2-stimulated cells did not change release significantly from control. Here, $n=16,13,6,7$, and 4 cells for control, $10 \mathrm{nM}$ "Estrogen stimulated", $10 \mathrm{nM}$ "Estrogen quiet", $50 \mu \mathrm{M}$ E2 "Estrogen stimulated", and $50 \mu \mathrm{M}$ E2 "Estrogen quiet", respectively. $* P<0.05$

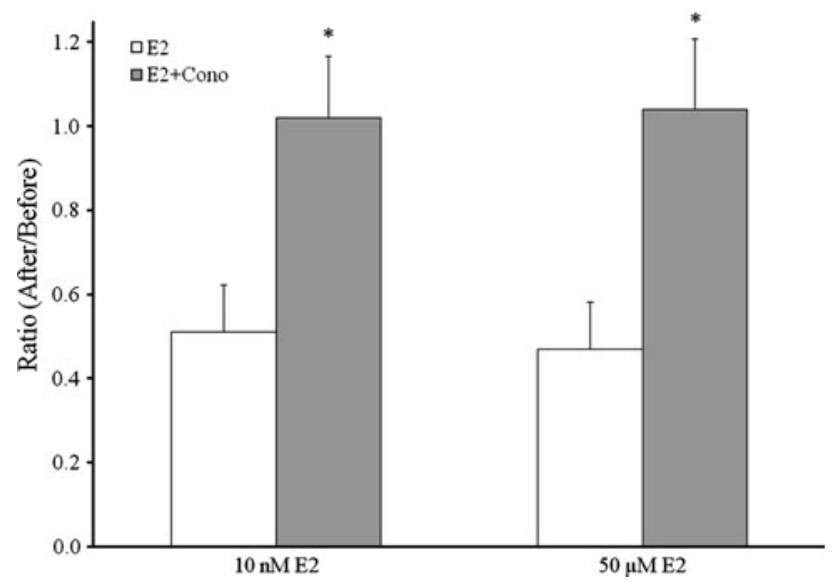

Fig. 5 E2-induced inhibition of exocytosis depends on N-type VGCCs in PC12 cells. Addition of $500 \mathrm{nM} \omega$-conotoxin (cono) to the bathing solution eliminated the decrease in exocytosis observed after $10 \mathrm{nME} 2$ and $50 \mu \mathrm{M}$ E2. Data are derived from "Estrogen-quiet" cells only (no E2-stimulated events during the treatment period). Data are collected from $n=6,4,12$, and 7 cells for $10 \mathrm{nM} \mathrm{E} 2,50 \mu \mathrm{M} \mathrm{E} 2,10 \mathrm{nM}$ $\mathrm{E} 2+$ cono, and $50 \mu \mathrm{M} \mathrm{E} 2+$ cono, respectively. $* P<0.05$

plasma membrane. The added E2-stimulated release in "Estrogen-stimulated" cells might deplete the vesicle pool available for further release and thereby reduce the number of exocytosis events observed with subsequent $\mathrm{K}^{+}$ stimulations.

As exocytosis was absent in "Estrogen-quiet" cells during E2 exposure, vesicle depletion cannot account for the observed inhibition of depolarization-evoked exocytosis. In these cells, the reduction of exocytosis by E2 at low and high concentrations was abolished in the presence of the N-type VGCC antagonist, $\omega$-conotoxin GVIA (Fig. 5), but not by the L-type VGCC antagonist nimodipine, indicating that E2-induced inhibition of N-type VGCCs accounts, at least partly, for the inhibition of exocytosis. Surprisingly, however, calcium imaging revealed that there is only an insignificant decrease in the calcium ratio after $50 \mu \mathrm{M}$ E2. This could imply that, in "Estrogen-stimulated" cells, E2-induced inhibition of N-type VGCC does not occur thus obscuring the calcium imaging data. It is also possible that a direct interaction between N-type VGCCs and the exocytotic machinery exists (for review see Atlas 2001) that is modulated by E2 resulting in effects on exocytosis in the absence of effects on calcium entry.

Thus, within the concentration range tested here $(10 \mathrm{pM}-100 \mu \mathrm{M})$, E2 non-linearly inhibits depolarizationevoked exocytosis. In "Estrogen-stimulated" cells, E2 induces exocytosis during exposure, possibly resulting in vesicle depletion. In "Estrogen-quiet" cells on the other hand, inhibition of N-type VGCCs accounts for the observed inhibition of depolarization-evoked exocytosis, providing another potential mechanism for the modulation of neuronal communication and plasticity in vivo.

The data presented here suggest that E2 modulates N-type VGCCs in neural transmission, and this could be important at any excitable cell type. Pharmacological treatment with estrogen might be problematic, however, owing to the complex concentration-response curve observed for treatment with E2. If PC12 cells can be taken as a model of adrenal cell behavior, then the presence of two cell types might also be a factor in governing the modulation of adrenal release of catecholamines by steroids.

Acknowledgments This study was supported by funding from the National Institutes of Health and the Swedish Science Research Council (Vetenskapsrådet or VR). A.G.E. is supported by a Marie Curie Chair from the European Union 6th Framework.

\section{References}

Atlas D (2001) Functional and physical coupling of voltage-sensitive calcium channels with exocytotic proteins: ramifications for the secretion mechanism. J Neurochem 77:972-985

Bennett DL, Bootman MD, Berridge MJ, Cheek TR (1998) $\mathrm{Ca}^{2+}$ entry into PC12 cells initiated by ryanodine receptors or inositol 1,4,5-trisphosphate receptors. Biochem J 329:349-357

Chen TK, Luo G, Ewing AG (1994) Amperometric monitoring of stimulated catecholamine release from rat pheochromocytoma (PC12) cells at the zeptomole level. Anal Chem 66:3031-3035 
Colliver TL, Hess EJ, Pothos EN, Sulzer D, Ewing AG (2000) Quantitative and statistical analysis of the shape of amperometric spikes recorded from two populations of cells. J Neurochem 74:1086-1097

Greene LA, Tischler AS (1976) Establishment of a noradrenergic clonal line of rat adrenal pheochromocytoma cells which respond to nerve growth factor. Proc Natl Acad Sci USA 73:2424-2428

Hirning LD, Fox AP, McCleskey EW, Olivera BM, Thayer SA, Miller RJ, Tsien RW (1988) Dominant role of N-type $\mathrm{Ca}^{2+}$ channels in evoked release of norepinephrine from sympathetic neurons. Science 239:57-61

Kelly MJ, Rønnekleiv OK (2009) Control of CNS neuronal excitability by estrogens via membrane-initiated signaling. Mol Cell Endocrinol 308:17-25

Kim YJ, Hur EM, Park TJ, Kim KT (2000) Nongenomic inhibition of catecholamine secretion by 17 betaestradiol in PC12 cells. J Neurochem 74:2490-2496

Kozminski KD, Gutman DA, Davila V, Sulzer D, Ewing AG (1998) Voltammetric and pharmacological characterization of dopamine release from single exocytotic events at rat pheochromocytoma (PC12) cells. Anal Chem 70:3123-3130

Lee DY, Chai YG, Lee EB, Kim KW, Nah SY, Oh TH, Rhim H (2002) 17Beta-estradiol inhibits highvoltage-activated calcium channel currents in rat sensory neurons via a non-genomic mechanism. Life Sci 70:2047-2059

Lopez MG, Abad F, Sancho C, Depascual R, Borges R, Maroto R, Dixon W, Garcia AG (1991) Membrane-mediated effects of the steroid 17- $\alpha$-estradiol on adrenal catecholamine release. J Pharmacol Exp Ther 259:279-285

Machado JD, Alonso C, Morales A, Gomez JF, Borges R (2002) Nongenomic regulation of the kinetics of exocytosis by estrogens. J Pharmacol Exp Ther 301:631-637
McCarthy MM (2008) Estradiol and the developing brain. Physiol Rev 88:91-134

Nilsen J (2008) Estradiol and neurodegenerative oxidative stress. Front Neuroendocrinol 29:463-475

Nilsen J, Mor G, Naftolin F (1998) Raloxifene induces neurite outgrowth in estrogen receptor positive PC12 cells. Menopause 5:211-216

Ogiue-Ikeda M, Tanabe N, Mukai H, Hojo Y, Murakami G, Tsurugizawa T, Takata N, Kimoto T, Kawato S (2008) Rapid modulation of synaptic plasticity by estrogens as well as endocrine disrupters in hippocampal neurons. Brain Res Rev 57:363-375

Sombers LA, Hanchar HJ, Colliver TL, Wittenberg N, Cans A, Arbault S, Amatore C, Ewing AG (2004) The effects of vesicular volume on secretion through the fusion pore in exocytotic release from PC12 cells. J Neurosci 24:303-309

Sombers LA, Wittenberg NJ, Maxson MM, Adams KL, Ewing AG (2007) High osmolarity and L-DOPA augment release via the fusion pore in PC12 cells. Chemphyschem 8:2471-2477

Taylor SC, Peers C (1999) Store-operated $\mathrm{Ca}^{2+}$ influx and voltagegated $\mathrm{Ca}^{2+}$ channels coupled to exocytosis in pheochromocytoma (PC12) cells. J Neurochem 73:874-880

Tully K, Treistman SN (2004) Distinct intracellular calcium profiles following influx through $\mathrm{N}$ - versus L-type calcium channels: role of $\mathrm{Ca}^{2+}$-induced $\mathrm{Ca}^{2+}$ release. J Neurophysiol 92:135-143

Vasudevan N, Pfaff DW (2007) Membrane-initiated actions of estrogens in neuroendocrinology: emerging principles. Endocr Rev 28:1-19

Westerink RH, Ewing AG (2008) The PC12 cell as model for neurosecretion. Acta Physiol 192:273-285

Westerink RH, de Groot A, Vijverberg HP (2000) Heterogeneity of catecholamine-containing vesicles in $\mathrm{PC} 12$ cells. Biochem Biophys Res Commun 270:625-630 